\title{
The Development of a Loop-Mediated Isothermal Amplification (LAMP) Procedure for Plague Diagnostic
}

\author{
Mariana de Lira Nunes, Carina Lucena Mendes-Marques, Alzira Maria Paiva de Almeida, \\ Nilma Cintra Leal ${ }^{*}$ \\ Departamento de Microbiologia, Centro de Pesquisas Aggeu Magalhães, FIOCRUZ-PE, Recife, Brazil \\ Email: nilma@cpqam.fiocruz.br
}

Received 10 September 2014; revised 30 October 2014; accepted 10 November 2014

Copyright (C) 2014 by authors and Scientific Research Publishing Inc.

This work is licensed under the Creative Commons Attribution International License (CC BY). http://creativecommons.org/licenses/by/4.0/

\section{(c) (i) Open Access}

\begin{abstract}
Plague caused by Yersinia pestis is one of the infectious diseases subject to the International Health Regulations (IHR). Permanent monitoring of the focal plague areas is mandatory in order to enable prompt control measures to prevent the spread of the disease. Therefore, the availability of efficient diagnosis tests is of paramount importance. Here, we describe a loop-mediated isothermal amplification (LAMP)-based procedure for rapid $Y$. pestis detection. We constructed a set of LAMP primers, which were used in assays to establish the reaction conditions that would lead to the quick visualization of the results by evaluating the test tube with the naked eye. The primers were specifically designed to target the caf1 gene located on pFra/Tox (pMT), a prototypical plasmid of $Y$. pestis. The LAMP procedure was performed at $65^{\circ} \mathrm{C}$ for $45 \mathrm{~min}$ in a water bath and allowed for the detection of at least $10 \mathrm{pg}$ of bacterial DNA. Due to its simplicity, specificity, sensitivity and rapidity, the LAMP technique is an additional tool that may be implemented in routine plague diagnoses, especially in emergencies.
\end{abstract}

\section{Keywords}

Plague, Yersinia pestis, Diagnosis Tests, Loop-Mediated Isothermal Amplification (LAMP)

\section{Introduction}

Yersinia pestis is a gram-negative bacterium of the Enterobacteriaceae family and is the causative agent of plague, a zoonotic disease of rodents (reservoirs) and their fleas (vectors), that affects humans and other mammals.

\footnotetext{
${ }^{*}$ Corresponding author.
} 
Depending on the transmission route, the human disease presents in different clinical forms; the most common are bubonic, septicemia and pneumonic plague [1]. Pneumonic plague is a potential public health emergency of international concern (PHEIC); therefore, any pneumonic case must to be immediately reported to the World Health Organization (WHO) [2].

In spite of all the technological advances and research, plague is still not eradicated. Human cases of the disease are reported annually to the WHO in various countries in Africa, Asia, the former Soviet Union and the Americas. The infection remains in natural foci that are strongly associated with people living in poor living conditions, those in extreme poverty. Currently, the WHO considers plague a reemerging disease with a trend of an increasing number of cases with geographical dispersion [3]-[5]. Thus, permanent monitoring of the focal plague areas is mandatory in order to trigger rapid and effective measures to control and prevent the spread of the disease. This requires the availability of adequate laboratory infrastructure, trained staff, and adequate supplies, including efficient diagnostic tests, which are difficult to acquire and use in poor resources countries.

We have previously developed several PCR-based procedures for identifying $Y$. pestis in biological samples [6]-[9]. While effective, these techniques require a high level of technical expertise and the use of expensive equipment for the reactions and visualization of the results.

The loop-mediated isothermal amplification (LAMP) technology, a variation of a PCR reaction, occurs at a constant temperature using the enzyme Bst polymerase and a set of four to six primers: two outer, two inner and two loop primers. The primers are specifically designed to amplify six to eight regions in the targeted gene. The outer primers participate in strand displacement during a non-cyclic step. The internal primers participate in the formation of a loop. The loop primers are optional and serve to accelerate the amplification reaction by binding to additional sites that are not accessed by the internal primers [10] [11].

The LAMP technology is quite simple, fast and inexpensive. It can be carried out in a water bath, and the results can be visualized directly through the test tube with the naked eye by observing the change of the reaction mix's turbidity caused by magnesium pyrophosphate accumulation in proportion to the amplified products [12] [13]. Eventually, the addition of chromogenic products may be necessary if the LAMP products cannot be visualized under natural light [14].

The aim of this study was to test the potential of LAMP technology for detection of $Y$. pestis for subsequent implementation in the diagnosis of plague. In this work, we constructed a set of primers that were specifically designed to target the caf1 gene. The caf1 gene, which is specific to Y. pestis, is located on the pFra/Tox plasmid which is also called pMT and is a prototypical Y. pestis plasmid [15] [16]. Many of the plague diagnostic techniques target this plasmid gene or detect its products [17]. The primers were used in assays to establish the reaction conditions. Amplification at $65^{\circ} \mathrm{C}$ for 45 min allowed for the detection of at least $10 \mathrm{pg}$ of $Y$. pestis DNA. Due to its specificity, sensitivity, rapidity and low cost, this LAMP procedure is an additional tool that may be implemented in the routine of plague diagnoses, especially in emergencies.

\section{Experimental Procedures}

\subsection{Bacterial Strains and Genomic DNA Extraction}

This study used the Y. pestis reference strain A1122 and the Brazilian strains P.Exu 369, P.Exu 390 and P.CE 882, Y. pseudotuberculosis IP32953, and one strain each of Vibrio cholerae (\#462), Listeria monocytogenes (\#226) and Pseudomonas aeruginosa (\#127) kindly provided by the Fiocruz-CYP, Institut Pasteur Paris and Laboratório de Zoonoses Bacterianas, Instituto Oswaldo Cruz (IOC/FIOCRUZ) collections. The culture conditions and genomic DNA extraction were performed as previously described [9] [17]-[19].

\subsection{Construction of the LAMP Primers}

The LAMP primers were built based on the analysis of sequences of the caf1 gene from the reference strain ( $Y$. pestis A1122) and the three Brazilian strains from different geographical, temporal and source origins (P.Exu 369, P.Exu 390 and P.CE 882). The caf1 gene is located on the pFra/Tox plasmid (pMT) [15] [16]. Many of the plague diagnostic techniques target this plasmid gene or detect its products [17].

\subsubsection{Amplification of the caf1 Gene from Y. pestis Strains by Conventional PCR (C-PCR)}

Y. pestis DNA from the strains A1122, P.Exu 369, P.Exu 390 and P.CE 882 was used to amplify a 513 bp (base pair) segment of the caf1 gene [15] by C-PCR using the method outlined by Leal et al. [6]. The reactions were 
made in $25 \mu \mathrm{L}$ of the reaction mixture composed of $50 \mathrm{mM} \mathrm{KCl,} 10 \mathrm{mM}$ Tris- $\mathrm{HCl}, 1.5 \mathrm{mM} \mathrm{MgCl}, 200 \mathrm{mM}$ dNTP, 20 pmol of each primer (F1F: CAGGGATCCATGAAAAAAATCAGTTC and F1R:

GGGCTCGAGTTGGTTAGATACGGTTA), 20 ng DNA, 1 U Taq DNA polymerase. The thermocycler conditions, which used a thermocycler (Biometra) included $3 \mathrm{~min}$ at $94^{\circ} \mathrm{C}$ and 30 cycles for $1 \mathrm{~min}$ at $94^{\circ} \mathrm{C}, 1 \mathrm{~min}$ at $55^{\circ} \mathrm{C}, 1 \mathrm{~min}$ at $72^{\circ} \mathrm{C}$, and $7 \mathrm{~min}$ at $72^{\circ} \mathrm{C}$. Then, $5 \mu \mathrm{L}$ of each of the PCR products was mixed with $5 \mu \mathrm{L}$ of the sample buffer $(0.25 \%$ bromophenol blue and $30 \%$ glycerol in water) and electrophoresed in $1 \%$ agarose gels plus $10 \mu \mathrm{L}$ of $\mathrm{SYBR}^{\circledR}$ Safe (Invitrogen) in $0.5 \%$ TBE at room temperature (RT) at $100 \mathrm{~V}-150 \mathrm{~mA}$ for 1 hour. The gels were observed under ultraviolet (UV) light and digitalized using the Kodak 1D Image Analysis Software, Version 3.5 (Digital Kodak Science). Each PCR run included a negative control without DNA.

\subsubsection{Purification of the C-PCR Products}

To $40 \mu \mathrm{L}$ aliquots of PCR products from each $Y$. pestis strain, $4 \mu \mathrm{L}$ of $3 \mathrm{M} \mathrm{NaCl}$ and $100 \mu \mathrm{L}$ of ethanol was added and incubated overnight at $-20^{\circ} \mathrm{C}$. The tubes were centrifuged at $20,000 \times \mathrm{g}$ for $10 \mathrm{~min}, 420 \mathrm{~mL}$ of $70 \%$ ethanol was added to the precipitate, re-centrifuged at 20,000 $\times \mathrm{g}$ for $10 \mathrm{~min}$ and the remaining pellet was suspended in $30 \mu \mathrm{L}$ of milli-Q water.

\subsubsection{Sequencing of the Purified C-PCR Products}

Purified C-PCR products were sequenced in an ABI Prism 3100 Genetic Analyzer (Applied Biosytems ${ }^{\circledR}$ ) by the Sanger method [20]. The sequences were analyzed by SeqMan ${ }^{\mathrm{TM}}$ and EditSeq ${ }^{\mathrm{TM}}$ (Lasergene $^{\circledR}$, Version 4.01, DNASTAR Inc., Madison, WI). A comparison with the caf1 sequence (accession number X61996.1) from the National Center for Biotechnology Information (NCBI) revealed a 100\% identity between the database sequence and the products. The BLAST (Basic Local Alignment Search Tool) analysis confirmed a high similarity with the other 26 caf1 sequences available at the NCBI.

\subsubsection{Design of the LAMP Primers}

Based on the sequences from C-PCR products, a set of five primers [two outer: forward (F3), backward (B3); two inner: forward (FIP), backward (BPI), and one backward loop primer (BLP)] were designed for the LAMP reaction (Table 1). The LAMP primers were designed using the Primer Explorer V4 software

(http://primerexplorer.jp/) (Eiken Chemical Co., Ltd.). The identification of the hybridizing sites was determined through MapDraw (Lasergene ${ }^{\circledR}$, Version 4.01, DNASTAR Inc., Madison, WI). The critical parameters [10], the GC (guanine-cytosine) content, Tm (melting temperature), stability of the final sequence of the primers, secondary structure formation and distance between primers, were analyzed. Integrated DNA Technologies (IDT) synthetized the LAMP primers. The use of HPLC (High-Performance Liquid Chromatography) purified internal primers is crucial for the production of LAMP primers [21]. Two sets of internal primers (FIP, BPI, Table 1) were produced and purified by HPLC and desalination, respectively.

\subsection{Quality Assessment of the Outer Primers (F3, B3)}

The quality of the F3 and B3 primers (Table 1) was assessed by C-PCR as described in Section 2.2.1 using 20 ng DNA from two $Y$. pestis cultures. For further confirmation, the products were purified and sequenced as described in Sections 2.2.2 and 2.2.3, respectively.

Assessment of the Hybridization Temperature of the Outer Primers (F3, B3)

The hybridization temperature of the F3 and B3 primers (Table 1) was assessed by C-PCR as described in

Table 1. LAMP primers for the caf1 gene of Yersinia pestis.

\begin{tabular}{cc}
\hline Primers & Sequences \\
\hline Forward outer primer (F3) & TCAGGATGGAAATAACCACCAA \\
Backward outer primer (B3) & GTTACGGTTACAGCATCAGTGTA \\
Forward inner primer (FIP) & CCACAAGGTTCTCACCGTTTACCTTCACTACAAAAGTGATTGGCAAGG \\
Backward inner primer (BIP) & GGATGACGTCGTCTTGGCTACGTGCAAGTTTACCGCCTTTGG \\
Backward loop primer (BLP) & GCAGCCAGGATTTCTTTGTTCGC \\
\hline
\end{tabular}


Section 2.2.1 using $20 \mathrm{ng}$ of $Y$. pestis DNA at a temperature gradient of $55^{\circ} \mathrm{C}$ to $65^{\circ} \mathrm{C}\left(55^{\circ} \mathrm{C}-55.2^{\circ} \mathrm{C}-55.8^{\circ} \mathrm{C}\right.$ $\left.56.7^{\circ} \mathrm{C}-57.8^{\circ} \mathrm{C}-59.1^{\circ} \mathrm{C}-60.4^{\circ} \mathrm{C}-61.7^{\circ} \mathrm{C}-62.9^{\circ} \mathrm{C}-63.9^{\circ} \mathrm{C}-64.6^{\circ} \mathrm{C}-65^{\circ} \mathrm{C}\right)$.

\subsection{Assessment of the Inner Primers (FIP, BPI) Quality}

The two sets of internal primers (FIP, BPI, Table 1) that were purified by either HPLC or desalination were used in comparative LAMP assays for efficacy at $65^{\circ} \mathrm{C}$ for $90 \mathrm{~min}$.

\subsection{Determination of the LAMP Reaction Time}

To determine the minimum incubation time for visualization of the amplified products, assays were carried out at increasing incubation times $(15,30,45,60,75$ and $90 \mathrm{~min})$ at $65^{\circ} \mathrm{C}$ using a thermocycler (Biometra) and a water bath in parallel. Reactions were performed with $20 \mathrm{ng}$ of $Y$. pestis A1122 DNA, the outer primers (F3, B3), the inner primers (FIP, BPI) and with or without the backward loop primer (BLP).

\subsection{Determination of Amplification Temperature for LAMP}

The amplification temperature for the LAMP was determined with assays performed for $60^{\circ} \mathrm{C}, 63^{\circ} \mathrm{C}$ and $65^{\circ} \mathrm{C}$ after 90 min using a thermocycler (Biometra) and a water bath in parallel. Reactions were performed with $20 \mathrm{ng}$ of $Y$. pestis A1122 DNA, the outer primers (F3, B3), the inner primers (FIP, BPI) and with or without the backward loop primer (BLP).

\subsection{Visualization of LAMP Products}

To evaluate the best mode of visualization, the products were stained by addition of the fluorescent dyes (1 $\mu \mathrm{L}: 10 \mu \mathrm{L}$ ). SYBR ${ }^{\circledR}$ Safe (Invitrogen) was used for the inspection with the naked eye, and SYBR ${ }^{\circledR}$ Green (Promega) was used for the inspection under UV. For comparison, the products were analyzed under UV light after electrophoresis was performed on $1 \%$ agarose gels and staining the gels with SYBR $^{\circledR}$ Green (Promega) as described in Section 2.2.1.

\subsection{Optimization of the LAMP Reaction Components}

The components of the reaction mixture were settled following a protocol based on the procedure described by Parida, et al. [10] varying the primers and dNTPs concentrations. The reactions were performed at $65^{\circ} \mathrm{C}$ for 90 min using a thermocycler (Biometra) and a water bath in parallel. Each assay included a negative control without DNA. The products were analyzed using electrophoresis and inspected using the naked eye and under UV light, as described in Section 2.7.

\subsection{Assessment of LAMP Sensitivity and Specificity}

The LAMP sensitivity was determined in parallel assays with C-PCR using serial dilutions (10 ng, $1 \mathrm{ng}, 100 \mathrm{pg}$, $10 \mathrm{pg}$ and $1 \mathrm{pg}$ ) of $Y$. pestis A1122 DNA. To determine the specificity of the reactions, the assays were performed in parallel with C-PCR using 20 ng DNA of the strains Y. pestis A1122, Y. pseudotuberculosis IP32953, Vibrio cholerae (\#462), Listeria monocytogenes (\#226) and Pseudomonas aeruginosa (\#127). All of the reactions included the outer primers (F3, B3), the inner primers (FIP, BPI) and the backward loop primer (BLP) and were performed at $65^{\circ} \mathrm{C}$ for $90 \mathrm{~min}$ using a thermocycler (Biometra) and a water bath in parallel. The C-PCR was performed as described in Section 2.2.1. The products were analyzed with electrophoresis and inspected by the naked eye and under UV light, as described in Section 2.7.

\section{Results}

\subsection{Assessment of the Outer Primers' (F3, B3) Quality and Hybridizing Temperature}

The segment of the expected size (207 bp) was amplified in the C-PCR reactions that were carried out in the listed temperatures between $55^{\circ} \mathrm{C}$ and $65^{\circ} \mathrm{C}$ (Figure 1). Aiming for a higher stringency, the $65^{\circ} \mathrm{C}$ temperature was adopted for the LAMP procedure. 


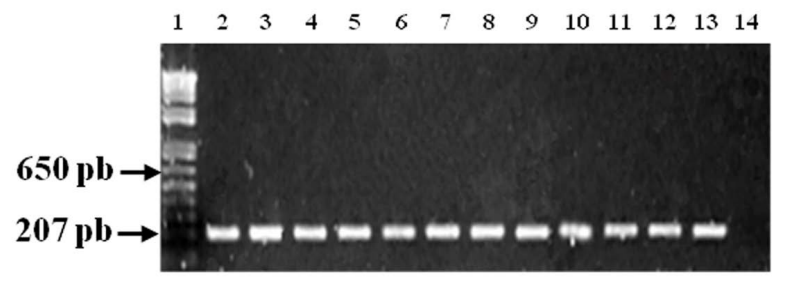

Figure 1. 1\% agarose gel electrophoresis of the C-PCR-amplified 207 bp segment of the gene caf1 with the outer primers (F3 and $\mathrm{B} 3$ ) at a temperature gradient of $55^{\circ} \mathrm{C}$ to $65^{\circ} \mathrm{C}$. Lane $1: 1 \mathrm{~Kb}$ plus DNA ladder; 2: $55^{\circ} \mathrm{C} ; 3: 55.2^{\circ} \mathrm{C} ; 4: 55.8^{\circ} \mathrm{C} ; 5: 56.7^{\circ} \mathrm{C} ; 6$ : $57.8^{\circ} \mathrm{C} ; 7: 59.1^{\circ} \mathrm{C} ; 8: 60.4^{\circ} \mathrm{C} ; 9: 61.7^{\circ} \mathrm{C} ; 10: 62.9^{\circ} \mathrm{C} ; 11: 63.9^{\circ} \mathrm{C}$; 12: $64.6^{\circ} \mathrm{C} ; 13: 65^{\circ} \mathrm{C}$; 14 : negative control.

\subsection{Assessment of the Inner Primers' (FIP, BPI) Quality}

Identical results were obtained with Y. pestis DNA and the inner (FIP, BPI) desalinized and the HPLC purified primers at $65^{\circ} \mathrm{C}$ after 90 min incubation. Because of this and the lower synthesis cost, desalinized primers were adopted.

\subsection{Determination of the LAMP Reaction Time}

In the reactions with $Y$. pestis DNA and the outer (F3, B3) and inner primers (FIP, BPI), the LAMP products were faintly detectable after $45 \mathrm{~min}$ of incubation, and after $60 \mathrm{~min}$ of incubation, the LAMP products were clearly detectable (Figure 2(a), Figure 2(b)). When the backward loop primer (BLP) was included, the products were clearly detectable at 45 min (Figure 2(c), Figure 2(d)). Identical results were obtained using a water bath or the thermocycler.

\subsection{Determination of the Amplification Temperature for LAMP}

Identical results were obtained with $Y$. pestis DNA and the outer (F3, B3), inner (FIP, BPI) and the backward loop primer (BLP) at the tested temperatures between $55^{\circ} \mathrm{C}$ to $65^{\circ} \mathrm{C}$ after a 90 min incubation (Figure 3(a), Figure 3(b)). Identical results were obtained using the water bath or the thermocycler. Aiming for a higher stringency, the $65^{\circ} \mathrm{C}$ temperature was adopted for the LAMP procedure.

\subsection{Standardization of LAMP Reaction Conditions}

The following conditions were established for the LAMP reactions: $25 \mu \mathrm{l}$ of reaction mixture was comprised of $40 \mathrm{pmol}$ of the inner primers (FIP, BPI), 10 pmol of the outer primers (F3, B3), 20 pmol of the backward loop primer (BLP), Tris-HCl (pH 8.8) $20 \mathrm{mM}$, (NH4) $\mathrm{SO}_{4} 10 \mathrm{mM}, \mathrm{MgSO}_{4} 8 \mathrm{mM}$, KCl $10 \mathrm{mM}$, dNTP $5.6 \mathrm{mM}$, Betaine $0.8 \mathrm{M}$, Tween-20 0.1\%, 8 U Bst DNA polymerase (New England Biolabs) and $20 \mathrm{ng}$ of $Y$. pestis DNA. The mixture was incubated for $45 \mathrm{~min}$ at $65^{\circ} \mathrm{C}$ using either a water bath or the thermocycler. The DNA must be denatured at $94^{\circ} \mathrm{C}$ for $5 \mathrm{~min}$ prior to using it in this mixture.

These conditions allowed for visualization of the amplified products under UV light upon the addition of SYBR $^{\circledR}$ Safe (Invitrogen) (Figure 4(a)) or visualizing the products by the naked eye by observing the color change from orange to green upon the addition of $\mathrm{SYBR}^{\circledR}$ Green (Promega) (Figure 4(b)). The amplification was confirmed by visualizing the products on $1 \%$ agarose gels stained with SYBR ${ }^{\circledR}$ Safe (Invitrogen) (Figure 4(c)).

\subsection{Sensitivity of the LAMP Technique}

In parallel assays using five dilutions containing $10 \mathrm{ng}$ to $1 \mathrm{pg}$ of purified $Y$. pestis A1122 DNA, the detection limit was 10 pg of DNA per LAMP or C-PCR reactions (Figures 5(a)-(c)).

\subsection{Specificity of the LAMP Technique}

In parallel assays with the LAMP and the C-PCR, only the DNA from the $Y$. pestis strain A1122 was amplified. No amplification was observed with the Y. pseudotuberculosis IP32953, V. cholerae (\#462), L. monocytogenes 


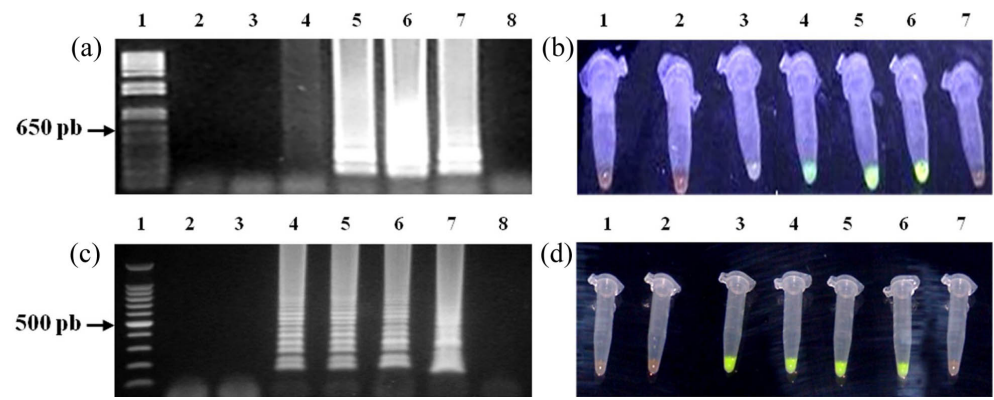

Figure 2. Inspection of LAMP products at the 15 - 90 min incubation times: (a) 1\% agarose gel electrophoresis. Lane 1: 1 Kb plus DNA ladder; 2: 15 min; 3: 30 min; 4: 45 min; 5: 60 min; 6: 75 min; 7: 90 min; 8: negative control; (b) Visualization of LAMP products stained with SYBR ${ }^{\circledR}$ Safe and inspected under UV light. Tubes: 1: 15 min; 2: 30 min; $3: 45$ min; $4: 60$ min; 5: 75 min; 6: $90 \mathrm{~min}$; : negative control; (c) 1\% agarose gel electrophoresis of the LAMP products including the BLP primer. Lanes 1: 1 Kb plus DNA ladder; 2: 15 min; 3: 30 min; 4: 45 min; 5: 60 min; 6: 75 min; 7: 90 min; 8: negative control; (d) Visualization of LAMP products including BLP primer stained with SYBR ${ }^{\circledR}$ Safe and inspected under UV light. Tubes: 1 : 15 min; 2: $30 \mathrm{~min}$; 3: $45 \mathrm{~min}$;: $60 \mathrm{~min}$; $75 \mathrm{~min}$; 6: $90 \mathrm{~min}$; 7: negative control.

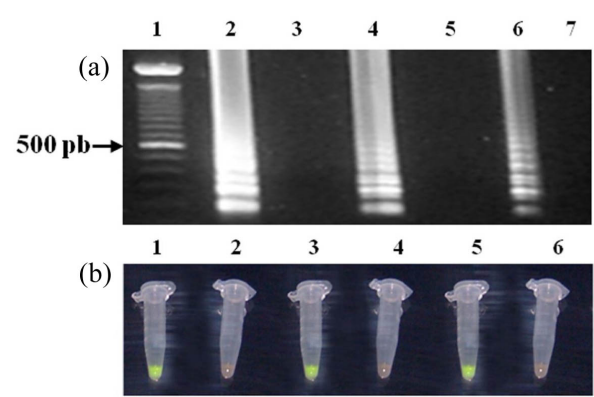

Figure 3. Inspection of LAMP products at the 60, 63, 65 min incubation times: (a) 1\% agarose gel electrophoresis. Lanes 1 : 100 pb DNA ladder; 2: $60^{\circ} \mathrm{C}$; 3: negative control; 4: $63^{\circ} \mathrm{C}$; 5: negative control; 6: $65^{\circ} \mathrm{C}$; 7: negative control; (b) Visualization of LAMP products stained with $\mathrm{SYBR}^{\circledR}$ Safe and inspected under UV light. Tubes 1 : $60^{\circ} \mathrm{C}$; 2: negative control; $3: 63^{\circ} \mathrm{C}$; 4 : negative control; 5: $65^{\circ} \mathrm{C}$; 6: negative control.

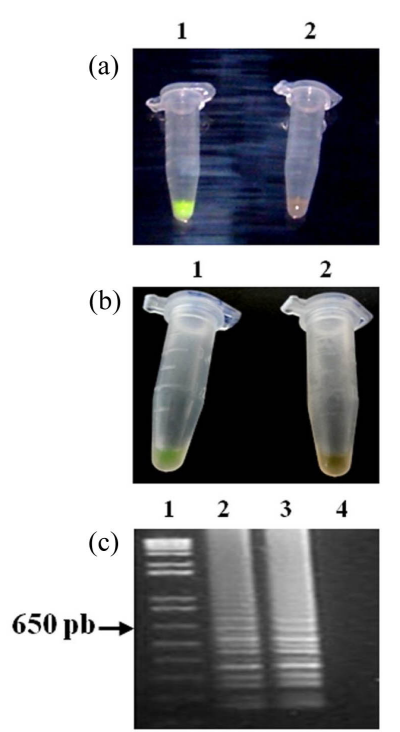

Figure 4. Inspection of LAMP products: (a) Visualization of LAMP products stained with SYBR ${ }^{\circledR}$ Safe and inspected under UV light. Tube 1 positive reaction, tube 2 negative reaction; (b) Visualization of LAMP products stained with SYBR ${ }^{\circledR}$ Green and inspected by the naked eye. Tube 1 positive reaction, tube 2 negative reaction; (c) $1 \%$ agarose gel electrophoresis of the LAMP products. Lanes 1: $1 \mathrm{~Kb}$ plus DNA ladder; 2-3: Y. pestis A1122; 4: negative control. 


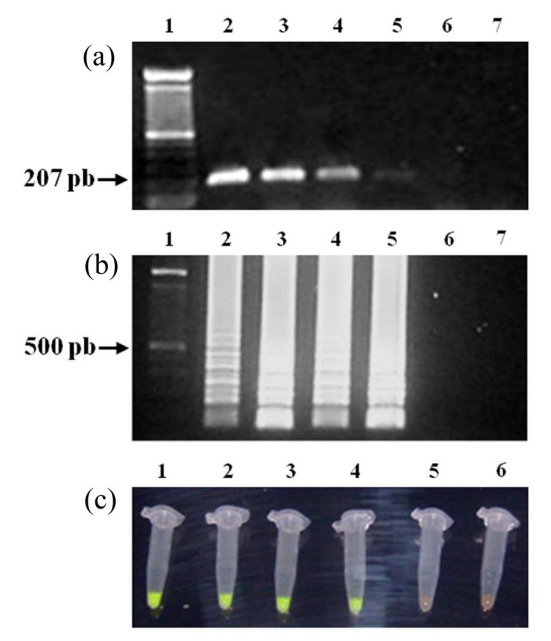

Figure 5. Assessment of LAMP sensitivity: (a) 1\% agarose gel electrophoresis of C-PCR, Lanes 1: 100 bp DNA ladder; 2: 10 ng; 3: 1 ng; 4: 100 pg; 5: 10 pg; 6: 1 pg; 7: negative control; (b) 1\% agarose gel electrophoresis of LAMP products. Lanes 1: 100 bp DNA ladder; 2: 10 ng; 3: 1 ng; 4: 100 pg; 5: 10 pg; 6: 1 pg; 7: negative control; (c) Visualization of LAMP products stained with SYBR ${ }^{\circledR}$ Safe and inspected under UV. Tubes 1: 10 ng; 2: 1 ng; 3: 100 pg; 4: 10 pg; 5: 1 pg; 6: negative control.

(\#226) or P. aeruginosa (\#127) strains (Figure 6(a), Figure 6(b)).

\section{Discussion}

One of the most important features of the LAMP technology is its simplicity. The only required equipment for DNA amplification is a water bath, which eliminates the need for a thermocycler, a complex and expensive piece of equipment. Furthermore, the visualization of the results is also equipment-free, which simplifies and reduces the cost of this technique. These characteristics make LAMP very attractive for use in resource-limited areas in developing countries and very important for the plague surveillance laboratories network [13].

Plague diagnosis employs bacteriological analyses to identify and isolate the bacteria, serological tests to detect anti-plague antibodies and molecular techniques to identify specific $Y$. pestis sequences [17]. The bacteriological diagnosis of plague may be hampered by the low quality of the samples collected in remote areas and improper shipping to the diagnosis laboratories [8] [22]. Molecular diagnostic techniques can occasionally replace bacterial culture and are feasible even when the bacteria are not viable or are from multi-contaminated samples. However, while effective, these techniques require a high level of technical expertise, the use of expensive equipment for the reactions and visualization of the results.

Considering the LAMP advantages, we developed a procedure for detecting the $Y$. pestis caf1 gene that was both specific and sensitive. At least $10 \mathrm{pg}$ of $Y$. pestis DNA were be detected in parallel reactions by LAMP and C-PCR, and no amplification was observed with other species tested than $Y$. pestis. The diagnostic rapidity is extremely important for plague surveillance and control. When the LAMP reaction was carried out at $65^{\circ} \mathrm{C}$ in a water bath, the reaction took 60 min using a set of four primers (two outer and two internal primers). The reaction time was reduced to $45 \mathrm{~min}$ by using the optional backward loop primer. Although the use of HPLC purified internal primers is emphasized by Tomita et al. [21], our results with desalinized- and HPLC-purified inner primers were similar, hence desalinized primers were adopted for our LAMP procedure, due to a lower synthesis cost.

The inspection of the LAMP products was improved by adding chromogenic products [14]. In this study, the LAMP products were visualized with the naked eye and under UV light with the addition of SYBR ${ }^{\circledR}$ Safe (Invitrogen) (Figure 4(a)) or using only visible light by observing a color change from orange to green with the addition of SYBR ${ }^{\circledR}$ Green (Promega) (Figure 4(b)). The amplification was confirmed by an agarose gel electrophoresis (Figure 4(c)).

In spite of all of the LAMP advantages, the risk of laboratory contamination by amplicons remains, as it does for other molecular techniques [21]. Therefore, for technical safety, the LAMP kits can be prepared in a central or reference laboratory and distributed to other laboratories with lower capabilities [13]. The use of the 


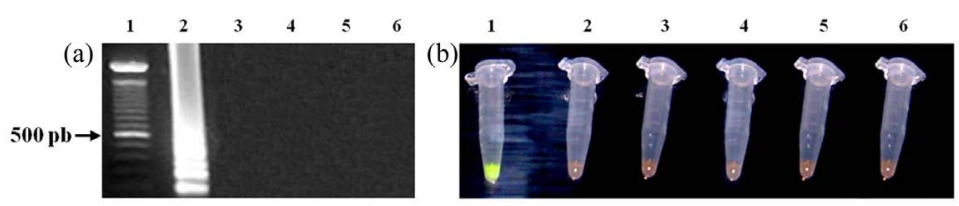

Figure 6. Assessment of LAMP specificity: (a) 1\% agarose gel electrophoresis of LAMP products. Lanes 1: 100 bp DNA ladder; 2: Y. pestis A1122; 3: Y. pseudotuberculosis IP32953; 4: L. monocytogenes (\#226); 5: P. aeruginosa (\#127); 6: V. cholerae (\#462); 7: negative control; (b) Visualization of LAMP products stained with SYBR ${ }^{\circledR}$ Safe and inspected under UV. Tubes 1: Y. pestis A1122 2: Y. pseudotuberculosis IP32953; 3: L. monocytogenes (\#226); 4: P. aeruginosa (\#127); 5: V. cholerae (\#462); 6: negative control.

pre-formulated test tubes could reduce errors in the reaction preparation and improve the efficiency of plague monitoring and control programs [8].

\section{Conclusion}

The LAMP technique is a simple, quick and inexpensive procedure that uses only a water bath. The result of this technique is visualized directly in the test tube by naked eye, thus dispensing the need for a thermocycler and electrophoresis. Due to its specificity, sensitivity, rapidity and low cost, this LAMP procedure represents an additional tool to use in routine plague diagnosis, especially in emergencies.

\section{Acknowledgements}

This work was supported by Fundação de Amparo a Ciência e Tecnologia do Estado de Pernambuco (FACEPE), Brazil, and by the Serviço Nacional de Referência em Peste (SRP), Brazil.

\section{References}

[1] Perry, R.D. and Fetherston, J.D. (1997) Yersinia pestis—Etiologic Agent of Plague. Clinical Microbiology Reviews, 10, 35-66.

[2] WHO (2008) International Health Regulations 2005. 2nd Edition, World Health Organization, Geneva, 74 p.

[3] Schneider, M.C., Najera, P., Aldighieri, S., Galan, D.I., Bertherat, E., Ruiz, A., Dumit, E., Gabastou, J.M. and Espinal, M.A. (2014) Where Does Human Plague Persist in Latin America? PLoS Negeted Tropical Diseases, 8, e2680. http://dx.doi.org/10.1371/journal.pntd.0002680

[4] Stenseth, N.C., Atshabar, B.B., Begon, M., Belmain, S.R., Bertherat, E., Carniel, E., Gage, K.L., Leirs, H. and Rahalison, L. (2008) Plague: Past, Present, and Future. PLoS Medicine, 5, e3. http://dx.doi.org/10.1371/journal.pmed.0050003

[5] WHO (2010) Human Plague: Review of Regional Morbidity and Mortality, 2004-2009. Weakly Epidemiology Record, 85, 40-48.

[6] Leal, N.C., Abath, F.G.C., Alves, L.C. and Almeida, A.M.P. (1996) A Simple PCR-Based Procedure for Plaque Diagnosis. Revista do Instituto de Medicina Tropical de São Paulo, 38, 371-373.

http://dx.doi.org/10.1590/S0036-46651996000500009

[7] Leal, N.C. and Almeida, A.M.P. (1999) Diagnosis of Plague and Identification of Virulence Markers in Yersinia pestis by Multiplex-PCR. Revista do Instituto de Medicina Tropical de São Paulo, 41, 339-342. http://dx.doi.org/10.1590/S0036-46651999000600002

[8] Silva, L.C., Vasconcelos, S.S., Mendes-Marques, C.L., Almeida, A.M.P. and Leal, N.C. (2012) Plague Diagnosis STNPCR and MPCR Kits Assembly, Reaction Reproducibility, and Reagent Stability. Advances in Experimental Medicine and Biology, 954, 143-147. http://dx.doi.org/10.1007/978-1-4614-3561-7 18

[9] Souza, G., Abath, F., Leal, N.C., Farias, A. and Almeida, A.M.P. (2007) Development and Evaluation of a Single Tube Nested-PCR Based Approach (STNPCR) for the Diagnosis of Plague. Advances in Experimental Medicine and Biology, 603, 351-359. http://dx.doi.org/10.1007/978-0-387-72124-8_32

[10] Parida, M., Sannarangaiah, S., Dash, P.K., Rao, P.V.L. and Morita, K. (2008) Loop Mediated Isothermal Amplification (LAMP): A New Generation of Innovative Gene Amplification Technique; Perspectives in Clinical Diagnosis of Infectious Diseases. Reviews in Medical Virology, 18, 407-421. http://dx.doi.org/10.1002/rmv.593

[11] Notomi, T., Okayama, H., Masubuchi, H., Yonekawa, T., Watanabe, K., Amino, N. and Hase, T. (2000) Loop-Mediated Isothermal Amplification of DNA. Nucleic Acids Research, 28, e63. http://dx.doi.org/10.1093/nar/28.12.e63 
[12] Mori, Y., Nagamine, K., Tomita, N. and Notomi, T. (2001) Detection of Loop-Mediated Isothermal Amplification Reaction by Turbidity Derived from Magnesium Pyrophosphate Formation. Biochemical and Biophysical Research Communications, 289, 150-154. http://dx.doi.org/10.1006/bbrc.2001.5921

[13] Njiru, Z.K. (2012) Loop-Mediated Isothermal Amplification Technology: Towards Point of Care Diagnostics. PLoS Neglected Tropical Diseases, 6, 1572-1575. http://dx.doi.org/10.1371/journal.pntd.0001572

[14] Chaudhary, A.A., Hemant, Mohsin, M. and Ahmad, A. (2011) Application of Loop-Mediated Isothermal Amplification (LAMP)-Based Technology for Authentication of Catharanthus roseus (L.) G. Don. Protoplasma, 249, 417-422. http://dx.doi.org/10.1007/s00709-011-0293-2

[15] Galyov, E.E., Smirnov, O.Y., Karlishev, A.V., Volkovoy, K.I., Denesyuk, A.I., Nazimov, I.V., Rubtsov, K.S., Abramov, V.M., Dalvadyanz, S.M. and Zav'yalov, V.P. (1990) Nucleotide Sequence of the Yersinia pestis Gene Encoding F1 Antigen and the Primary Structure of the Protein: Putative T and B Cell Epitopes. FEBS Letters, 277, 230-232. http://dx.doi.org/10.1016/0014-5793(90)80852-A

[16] Prentice, M.B. and Rahalison, L. (2007) Plague. The Lancet, 369, 1196-1207. http://dx.doi.org/10.1016/S0140-6736(07)60566-2

[17] Chu, M. (2000) Laboratory Manual of Plague Diagnostic Tests. Centers for Disease Control and Prevention, World Health Organization.

[18] Leal, N.C., Silva, S.C., Cavalcanti, V.O., Figueiroa, A.C.T.A., Nunes, V.V.F., Miralles, I.S. and Hofer, E. (2008) Vibrio parahaemolyticus Serovar O3:K6 Gastroenteritis in Northeast Brazil. Journal of Applied Microbiology, 105, 691697. http://dx.doi.org/10.1111/j.1365-2672.2008.03782.x

[19] Costa, A.P.R., Vilela, M.A., Mendes-Marques, C.L., Almeida, A.M.P. and Leal, N.C. (2013) Biochemical and Molecular Characteristics of Listeria monocytogenes Isolates from a Prosthetic Mitral Heart Valve-Bearing Patient's Blood Cultures. Journal of Health \& Biological Science, 1, 161-121.

[20] Sanger, F., Nicklen, S. and Coulson, R. (1977) DNA Sequencing with Chain-Terminating Inhibitors. Proceedings of the National Academy of Sciences of the United States of America, 74, 5463-5467.

[21] Tomita, N., Mori, Y., Kea, H. and Notomi, T. (2008) Loop-Mediated Isothermal Amplification (LAMP) of Gene Sequences and Simple Visual Detection of Products. Nature Protocols, 3, 877-882. http://dx.doi.org/10.1038/nprot.2008.57

[22] Melo, A.C., Almeida, A.M.P. and Leal, N.C. (2003) Retrospective Study of a Plague Outbreak by Multiplex-PCR. Letters in Applied Microbiology, 37, 361-364. http://dx.doi.org/10.1046/j.1472-765X.2003.01377.x 
Scientific Research Publishing (SCIRP) is one of the largest Open Access journal publishers. It is currently publishing more than 200 open access, online, peer-reviewed journals covering a wide range of academic disciplines. SCIRP serves the worldwide academic communities and contributes to the progress and application of science with its publication.

Other selected journals from SCIRP are listed as below. Submit your manuscript to us via either submit@scirp.org or Online Submission Portal.
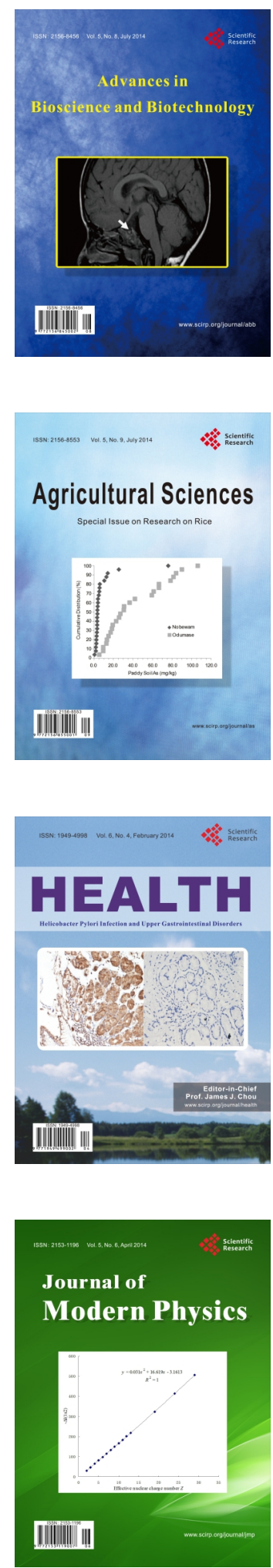
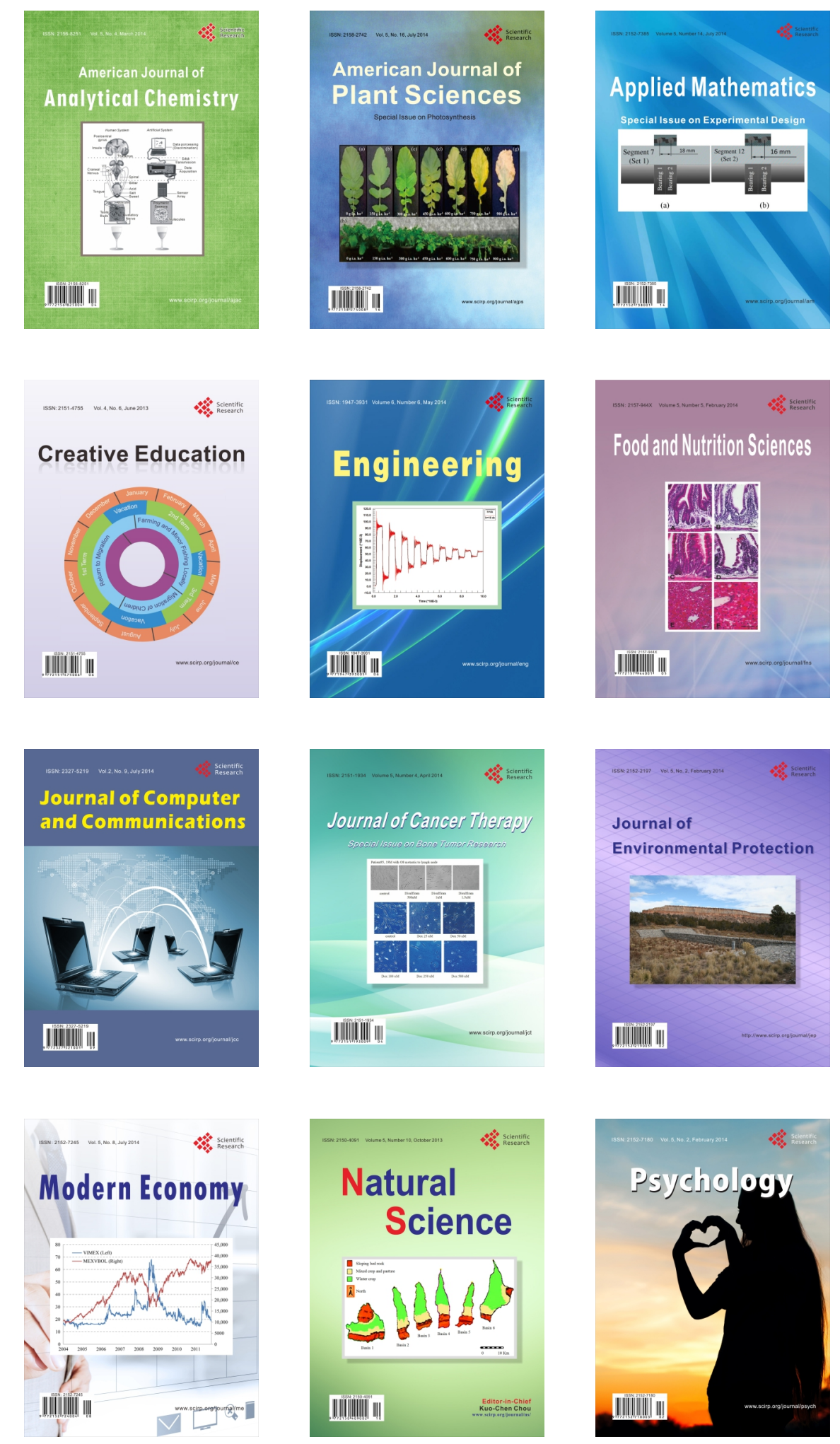